\title{
Process Designs for Converting Propylene Glycol to Acrylic Acid via Lactic Acid and Allyl Alcohol
}

\author{
M. M. Buitelaar, ${ }^{\dagger, \S}$ E. van Daatselaar, ${ }^{\dagger, \S}$ D. G. van Teijlingen, ${ }^{\dagger, \S}$ H. I. Stokvis, ${ }^{\dagger, \S}$ J. D. Wendt, ${ }^{\dagger, \S \odot ~}$ \\ R. J. De Sousa Ribeiro, ${ }^{\dagger, \S}$ A. M. M. Brooks, ${ }^{\dagger}$ E. C. Kamphuis, ${ }^{\dagger}$ S. Lopez Montoya, ${ }^{\dagger}$ J. C. van Putten, ${ }^{\dagger}$ \\ A. G. J. van der Ham, ${ }^{* \dagger}$ H. van den Berg, ${ }^{\dagger}$ and J.-P. Lange ${ }^{\dagger,+\infty}$ \\ ${ }^{\dagger}$ Sustainable Process Technology, Faculty of Science and Technology, University of Twente, P.O. Box 217, 7500 AE Enschede, \\ Netherlands \\ ${ }^{\ddagger}$ Shell Technology Center Amsterdam, Grasweg 31, 1031 HW Amsterdam, Netherlands \\ Supporting Information
}

ABSTRACT: The chemical industry is currently facing the challenge of developing biobased production processes suitable for a more sustainable chemical industry. Acrylic acid produced from monopropylene glycol is a good candidate to become a cost-competitive and sustainable platform chemical. The propylene glycol price is expected to drop due to the expected abundance of propylene glycol as a sugar hydrogenolysis byproduct, which is required to make the conversion to acrylic acid cost-competitive. Two different processes for the conversion of propylene glycol to acrylic acid are evaluated in this work, either by (1) low temperature oxidation of propylene glycol to lactic acid and high

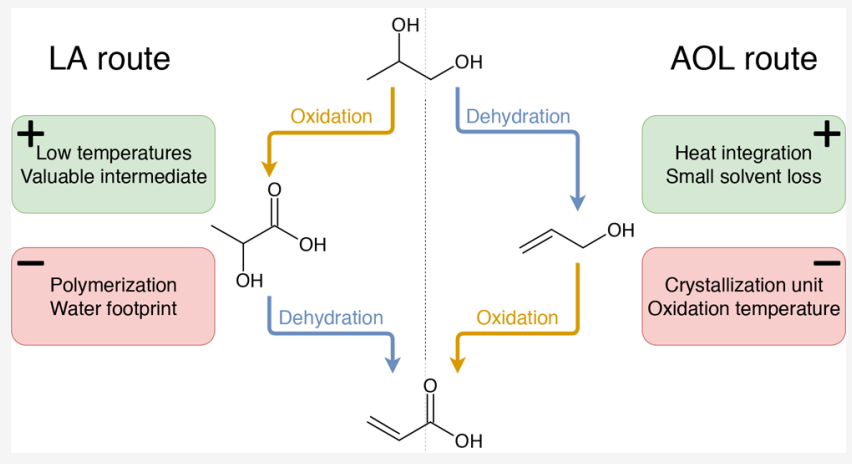
temperature dehydration to acrylic acid or by (2) high temperature dehydration of propylene glycol to allyl alcohol and further high temperature oxidation to acrylic acid. Liquidliquid extraction was found to be a key operation in both production processes. At similar overall yields, the allyl alcohol route appears inherently favored, as a result of the opportunity to integrate the reaction heat available at high temperature. To conclude, the price of propylene glycol has to drop by $45-55 \%$ to make the biobased production of acrylic acid from propylene glycol economically feasible.

\section{INTRODUCTION}

Acrylic acid (AcrA) is an important industrial organic chemical that is widely used as a raw material to produce coatings, paints, adhesives, and superabsorbents. ${ }^{1}$ The global market of acrylic acid represented $8 \mathrm{Mta}$ in $2017^{2}$ and is one of the fastest growing high-value platform chemicals with an annual demand growth of $4 \%^{3}$ at a price of $\$ 2,000 / \mathrm{t} .^{2}$ The commercial production of AcrA relies on fossil fuels since it is commonly produced from the oxidation of oil-based propylene. Alternative sugar-based production processes have been proposed, e.g., via fermentation to lactic acid or 3hydroxypropionic acid or via hydrogenolysis to propylene glycol. ${ }^{2}$ The market size for sugars was 179 Mta in $2018 .^{4}$

The market for short polyols, such as ethylene glycol, produced from sugars is expected to grow tremendously in the future. This process will coproduce significant amounts of propylene glycol $(\mathrm{PG})^{5,6}$ that could readily flood its limited market, which is now approximately $2.5 \mathrm{Mta}^{7}$ Upgrading of PG to a product with a larger market, such as AcrA, would therefore be beneficial.

Elementary economic considerations reveal that AcrA can not afford PG as a feedstock at present market prices of around
$\$ 2,000 / \mathrm{t}$ and $\$ 2,200 / \mathrm{t}$, respectively. The current PG market is 20-fold smaller compared to the current EG market. Therefore, the price is expected to drop rapidly due to flooding of the market when coproduced with EG, possibly down to the EG price level of around $\$ 900 / \mathrm{t}^{8}$

Pramod et al. investigated two different pathways for conversion of PG into AcrA. ${ }^{2}$ The first route is performed by oxidation of PG to lactic acid (LA) and consecutively dehydration to AcrA. This will be denoted as the LA route. The second chemical pathway in this research is the dehydration of PG to allyl alcohol (AOL) followed by oxidation to AcrA, and is denoted here as the AOL route. ${ }^{2}$ Both pathways are displayed with structural formulas in Figure 1 .

Neither of the two routes is intrinsically favored over the other at the current high level analysis. A detailed process

Received: August 6, 2019

Revised: December 18, 2019

Accepted: December 20, 2019

Published: December 20, 2019 


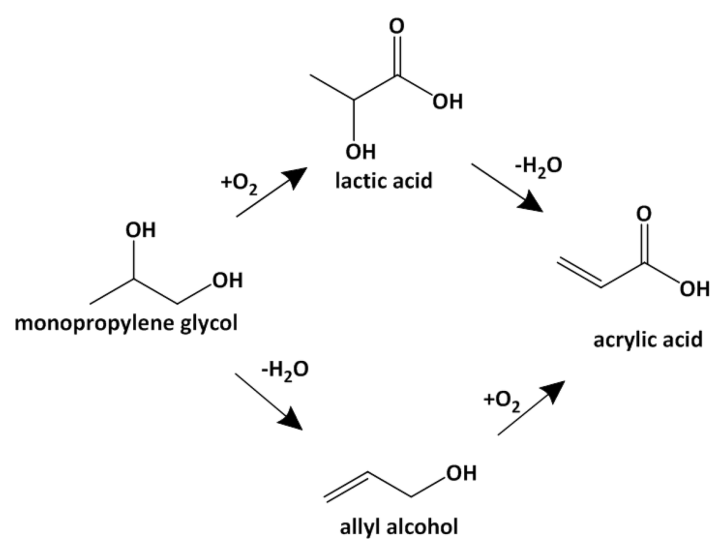

Figure 1. Reaction routes for conversion of propylene glycol to acrylic acid. Upper route via lactic acid, LA route; lower route via allyl alcohol, AOL route. Reproduced with permission from ref 2 . Copyright 2018 The Royal Society of Chemistry.

design and techno-economic evaluation in this paper will provide more grounding to find the most promising route.

Both routes are independently reviewed and subjected to a complete conceptual process design in this paper. A systematic methodology to construct a process design based on the Douglas method ${ }^{9}$ is used, starting from a black box setup. This process design is optimized to find the most favorable separation train and opportunities for heat integration. Sizing and material selection is done for the major units, which results in a high level evaluation of capital expenditures (CAPEX), operational expenditures (OPEX), and break-even price of the raw material. Besides, both processes are evaluated on technical aspects as level of heat integration, solvent losses, and sustainability. Important parameters that are used are depicted in Table 1.

Table 1. Economic Values Used in This Article

\begin{tabular}{llll} 
& value & \multicolumn{1}{c}{ units } & source \\
plant capacity & 150 & kt annually & - \\
desired acrylic acid purity & 99.6 & wt $\%$ & 12 \\
acrylic acid market price & 2,000 & $\$ / \mathrm{t}$ & 2 \\
propylene glycol market price & 2,200 & $\$ / \mathrm{t}$ pure PG & 2 \\
electricity price & 0.06 & $\$ / \mathrm{kWh}$ & 13 \\
fuel gas price & 6 & $\$ / \mathrm{GJ}$ & 13 \\
solvent price (DIPE/octanol) & 1,000 & $\$ / \mathrm{t}$ & - \\
operator wage & 60,000 & $\$ /$ operator/year & 13 \\
no. operators & 4.5 & operators/shift & 13 \\
number of shifts & 5 & & 14 \\
operation hours & 8,000 & $\mathrm{~h} /$ year & 13 \\
location factor (Southeast Asia) & 1.12 & & 13 \\
Lang factor & 4.74 & & 14 \\
depreciation & 10 & years & 14 \\
CEPCI value (2017) & 567.5 & & 15 \\
\hline
\end{tabular}

This research is performed by two teams of five master's students each as part of the course Process Plant Design (PPD). These projects resulted in two extensive reports of about 150 pages each, which contain all calculations, assumptions, and decisions made upon detailed design. ${ }^{10,11}$ These reports can be requested from the corresponding author (A. G. J. van der Ham). Because of space limitations, the present paper will limit itself to discussing the final process flow schemes and their techno-economic analysis.
The main research objective of this article is to find the required drop in market price of PG to enable an economically viable biobased production of acrylic acid. Moreover, the most intrinsically favored route needs to be determined and the process elements with the highest impact on the process viability need to be identified.

\section{CHEMISTRY}

A detailed literature search as reported in the Supporting Information identified suitable process conditions and catalysts for all process steps as indicated in Figure 1. In Table 2 an overview of these parameters is given. For the LA route, it is chosen to perform the PG oxidation step in the liquid phase using $\mathrm{Au}_{0.75} \mathrm{Pd}_{0.25} /$ hydroxyapatite as catalyst and to run the $\mathrm{LA}$ dehydration step in the gas phase using KZSM-5 as catalyst. $^{16,17}$ For the AOL route, the PG dehydration is operated in gas phase using scandium oxide as catalyst and the AOL oxidation runs in the gas phase using $\mathrm{Mo}-\mathrm{V}-\mathrm{W}-\mathrm{O}$ as catalyst. ${ }^{18,19}$ The catalytic performance found in the literature is likely not optimized for process design as this concerns results of a catalyst screening program in the laboratory. It is therefore chosen to assume an identical overall yield of 75.1 $\mathrm{mol} \%$ for both routes for further comparison, although the LA route shows lower yields in Table 2 . The conversion of the reactions is not limited by equilibrium.

2.1. Process Challenges. Analysis of possible catalysts gave insight into the reactions and the chemical components involved in both processes. These insights raised some main challenges which are based on the nature of the involved reactions and compounds. The major challenge in the LA route is the tendency of LA to polymerize when present in high concentrations. This requires a relatively high degree of dilution and may be problematic when evaporating the mixture. The AOL route might be challenged by the nature of both reactions to be at high temperatures. Sophisticated and extensive cooling systems will be required to provide stability in the exothermic oxidation reactor at high temperatures.

\section{METHODOLOGY}

The process was designed in a systematic way according to the method developed by Douglas ${ }^{9}$ and adapted by others, e.g., by Seider et al. ${ }^{13}$ A decision tree was developed to visualize the relationship between input variables and design objectives. It started with an overall process analysis, which documents all design steps, including decisions and loops in the design activities. Then, the process functions required to convert raw materials into products were defined to identify process alternatives. This was followed by further detailing the functional blocks and lining them up in preliminary process flow sheets based on new and conventional technologies.

In line with Seider et al., ${ }^{13}$ each process operation had a role in eliminating one or more of the property differences between the raw materials and the products. The first step was to eliminate differences in molecular type; this was done by chemical reaction in the function of a reactor, the heart of a chemical process. Raw materials were not converted for $100 \%$ into the desired product, so one or more separation functions were also needed. Various alternatives were sketched and the least attractive were rejected without being detailed, as recommended by Douglas. 9 Several iterations were done between the generation and the selection. The final flow sheet was developed with Aspen Plus V10. 
Table 2. Overview of Reported Catalytic Performance for Both Routes

\begin{tabular}{|c|c|c|c|c|c|c|c|c|}
\hline & catalyst & $T\left[{ }^{\circ} \mathrm{C}\right]$ & $P[$ bar $]$ & $\begin{array}{l}\text { conversion } \\
{[\mathrm{mol} / \mathrm{mol}]}\end{array}$ & $\begin{array}{l}\text { selectivity } \\
{[\mathrm{mol} / \mathrm{mol}]}\end{array}$ & $\begin{array}{l}\text { reaction enthalpy } \\
{[\mathrm{kJ} / \mathrm{mol} \text { reactant }]}\end{array}$ & byproducts & ref \\
\hline \multicolumn{9}{|l|}{ LA route } \\
\hline oxidation & $\mathrm{Au}_{0.75} \mathrm{Pd}_{0.25} / \mathrm{HAP}$ & 80 & 1 & 0.966 & 0.971 & -409 & FA, AOL & 16 \\
\hline dehydration & KZSM-5 & 365 & 1.5 & 0.96 & 0.78 & 59 & $\mathrm{AL}, 2,3-\mathrm{PD}, \operatorname{PrA}$ & 17 \\
\hline \multicolumn{9}{|l|}{ AOL route } \\
\hline dehydration & $\mathrm{Sc}_{2} \mathrm{O}_{3}$ & 350 & 1 & 0.98 & 0.85 & 64 & $\begin{array}{l}\text { PAL, POL, MCP, } \\
\text { DPG }\end{array}$ & 18 \\
\hline oxidation & $\mathrm{Mo}-\mathrm{V}-\mathrm{W}-\mathrm{O}$ & 325 & 1 & 1 & 0.901 & -449 & AceA, PG, $\mathrm{CO}_{2}, \mathrm{CO}$ & 19 \\
\hline
\end{tabular}

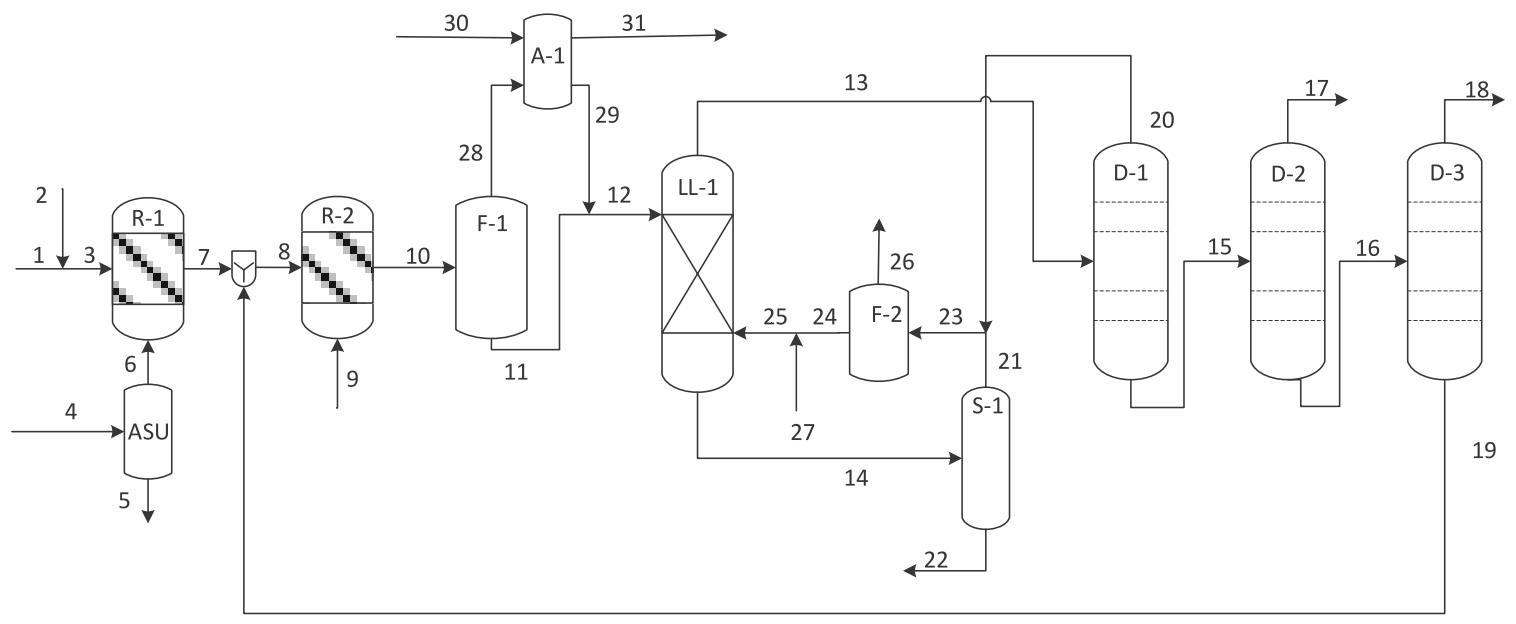

Figure 2. Simplified process flow diagram of the LA route. Pumps, compressors, and heat exchangers are not shown.

The project was finalized with a detailed design of the units, heat integration, control, safety, sustainability analysis, and a techno-economic evaluation. Each route was designed by a different different team working independently of the other, which explains differences in design choices.

3.1. Thermodynamic Model. For the LA route, the polar nature of the reactor effluent was a reason to choose the NRTL property method to model the liquid phase. Solubility and extraction model parameters were checked with data from the Dechema Data Series. ${ }^{20,21}$ The vapor phase was modeled by the Hayden-O'Connell method, to take the possible associative behavior of vapor-phase acids into account.

Real vapor-liquid equilibrium data from the Dechema Data Series ${ }^{20,21}$ were compared with vapor-liquid equilibrium data of NRTL and UNIQUAC methods in Aspen Plus. These were respectively used in modeling the atmospheric and vacuum operations for the AOL route. Missing parameters were estimated using UNIFAC.

3.2. Heat Integration. The pinch analysis as described by $\mathrm{Kemp}^{22}$ is used to analyze the possiblities for heat integration. Heat integration was applied where possible and efficient, using the freeware of the University of Lisbon. ${ }^{23}$ The minimum approach temperature is set to $15^{\circ} \mathrm{C}$, which is commonly used for gas-fluid processing plants. ${ }^{14}$

3.3. Economics. Basic design methods were used to determine the dimensions of the equipment. Cost estimation data were retrieved from several different sources ${ }^{13,14,24-26}$ to determine the free on board (FOB) price of equipment. All estimations were corrected with the chemical engineering plant cost index (CEPCI) value of 2017 of 567.5 (Table 1)..$^{5}$ To account for additional costs, such as installation, process control systems, and piping, the factor method is used and the FOB price is multiplied by a Lang factor of 4.74 , which is a typical factor for fluid processing plants. ${ }^{14}$ This method typically has an accuracy of $30 \%$ in absolute terms. For comparative analysis, however, the method is expected to be more accurate than $30 \%$, particularly in the present case that compares very similar processes. The location of the plants is set to South-East Asia and a factor of 1.12 (U.S. Gulf Coast = $1.00)$ is incorporated as the location factor. ${ }^{14}$ An estimation of the operational expenditures is made based on the work of Seider et al. $^{13}$

\section{PROCESS DESIGN RESULTS}

For each route the optimal design of the flow sheet, reactors, main separation units, and heat integration will be discussed, including the most important decisions. Both processes should produce $150 \mathrm{kta}$ AcrA with 99.6 wt \% purity. As discussed in section 2 , the overall yield for both processes is assumed to be $75.1 \%$. The feed stream for both processes is a diluted aqueous PG stream containing $50 \mathrm{~mol} \%$ PG, which results in an aqueous PG stream of around $260 \mathrm{kta}$ as feedstock.

4.1. LA Route. 4.1.1. Flow Sheet Description. As illustrated in Figure 2, the predetermined PG feedstock (1) is diluted with water (2) in the first place to obtain a stream of processable viscosity and second to reach the target selectivity as reported in the literature. Pure oxygen supplied by an offthe-shelf air separation unit (ASU) is bubbled into the oxidation reactor to ensure high catalyst performance. The liquid phase oxidation reactor $(\mathrm{R}-1)$ is operated at $80{ }^{\circ} \mathrm{C}$ and 1 bar. The oxidation reaction reaches a $100 \%$ conversion to avoid subsequent product workup between the reactors. Lactate is the main oxidation product, and acidification with hydrochloride is required to obtain LA. This acidification is performed in stream 7 and can lead to the formation of solids, which are removed with a filtration unit. It is assumed that the 
filtration unit will not give a significant product loss, because of the high dilution in water. The intermediate product stream is pressurized and heated before it is fed to the second reactor. The dehydration gas-phase reactor (R-2) operates at $365{ }^{\circ} \mathrm{C}$ and 1.5 bar. The effluent is cooled and sent to a phase separator (F-1) removing the volatiles from the liquid product stream. Traces of AcrA (29) are recovered from the volatiles (28) by a gas absorber (A-1). The volatiles (mainly $\mathrm{N}_{2}, \mathrm{H}_{2} \mathrm{O}$, $\mathrm{CO}_{2}$, and $\mathrm{CO}$ ) leave the system (31). The liquid stream of F-1 which mainly contains $\mathrm{H}_{2} \mathrm{O}$ and AcrA (12) flows to a liquidliquid extractor (LL-1) where it is contacted countercurrently with a solvent (DIPE, see section 4.1.3). A stripper (S-1) is used to recover the solvent (21) from the aqueous-rich stream from the extraction (14), leaving an aqueous stream with low solvent content (22). After extraction the mixture (13) goes to a separation train consisting of three distillation columns: the first column (D-1) removes the solvent (20), the second column (D-2) removes the water (17), and the third column (D-3) purifies the AcrA to 99.7 wt \% as distillate (18). The third column is a vacuum distillation that operates at lower temperature to avoid AcrA decomposition. While no recycle of LA was initially needed due to high conversion in R-2, relatively pure LA is obtained from D-3, which is easily recycled to R-2. The LA-rich stream (19) is partly purged (not shown) to prevent accumulation of heavies in the system. The solvent is recovered as the top fraction of D-1, of which the vapor part is compressed to the desired pressure of 2.5 bar and liquefied. The entire stream of solvent is sent back to LL-1. A makeup stream (27) is added to the distillate of D-1 (24) to compensate for solvent losses in S-1 (22) and F-2 (26). All units shown in Figure 2 are within battery limits including the pumps, compressor, and vessels which are now excluded from the flow sheet.

The quantities and conditions of the most important process streams for the LA route are given in Table 3. The concentration of propionic acid (PrA), which boils very close to AcrA, is low enough to meet the product purity specification without any further purification steps after distillation. This component is not explicitly mentioned in Table 3 , but it is represented as part of the "byproduct" stream.

4.1.2. Reactor Design. The reactor type used for the design of the liquid-phase oxidation (R-1) is a slurry bubble column. Bubble columns provide sufficient mass transfer to disperse the oxygen gas bubbles in the liquid phase, where the reaction takes place. As the reaction is highly exothermic $\left(\Delta_{\mathrm{r}} H=-409\right.$ $\left.\mathrm{kJ} / \mathrm{mol} \mathrm{PG}, \Delta T_{\mathrm{ad}}=857 \mathrm{~K}\right)$, vertical cooling tubes are used to remove the $43 \mathrm{MW}$ excess heat from the reactor, which is proposed by Schlüter et al., ${ }^{27}$ to maintain its temperature of 80 ${ }^{\circ} \mathrm{C}$. Gas and liquid inlets are supplied to the reactor countercurrently. The catalyst is dispersed in the liquid phase. The liquid outlet stream is equipped with a filter to keep the catalyst in the reactor. The gas stream is introduced in the bottom to ensure a homogeneous catalyst distribution in the reactor.

The gas phase reactor (R-2) requires evaporating LA dissolved in water before it enters the reactor. Due to the large differences in volatility between water and LA, simple evaporation would lead to LA polymerization and the subsequent accumulation of solid polylactic acid (PLA) would cause clogging and fouling of the reactor. Spray evaporation in hot flue gas is selected here ${ }^{28}$ to ensure rapid evaporation, thereby minimizing the risk of LA polymerization.

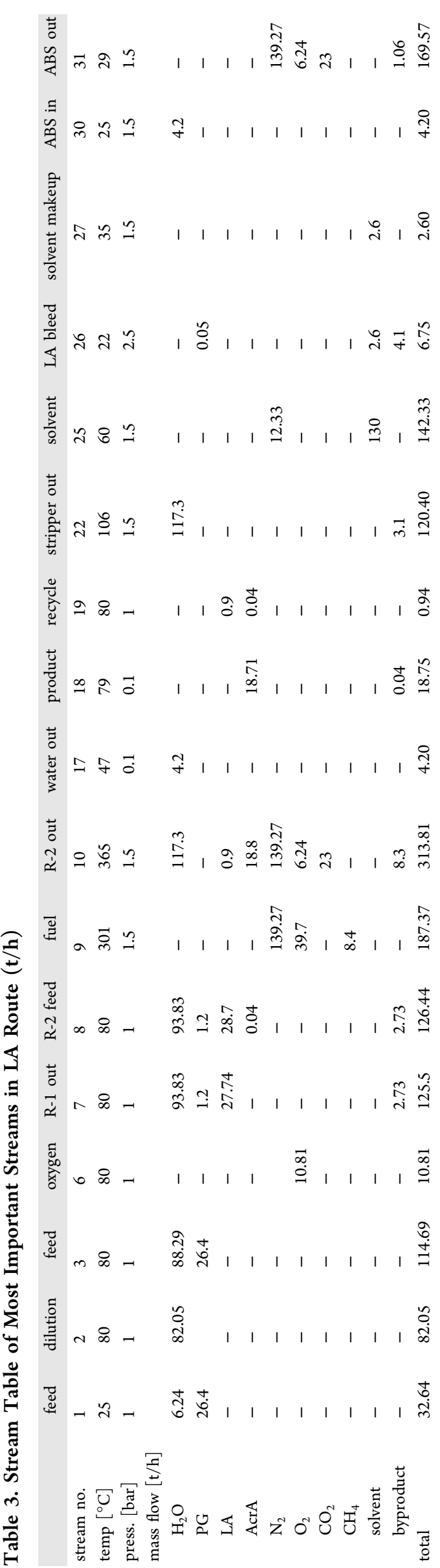


Obviously this choice does not allow for a feed-effluent heat exchanger and, thereby, reduces options for heat integration.

The spray evaporator is equipped with a nozzle which disperses the aqueous LA mixture into droplets above the gas inlet and is heated instantaneously by the hot gas stream. This stream is produced by burning natural gas in air, and its inlet is located at the bottom of the unit. The vapor containing LA flows upward through the fixed beds where the LA will dehydrate over the catalyst. The spray evaporator technology is integrated in the bottom of the dehydration reactor. The endothermic reactor $\left(\Delta_{\mathrm{r}} H=59 \mathrm{~kJ} / \mathrm{mol}\right.$ reactants, $\Delta T_{\mathrm{ad}}=-73$ $\mathrm{K})$ is equipped with an interstage heating system in which hot gas can be injected to provide the heat duty of $5 \mathrm{MW}$ to keep the reactor at $365{ }^{\circ} \mathrm{C}$.

4.1.3. Main Separation Unit. Different unit operations are considered for purification of the hot gas phase reactor effluent, containing mostly AcrA, water, and LA. Cooling the effluent to $35{ }^{\circ} \mathrm{C}$ will introduce an optimal phase split to separate the volatiles from the liquid product stream. Four alternatives are considered for recovering AcrA from the highly diluted stream: distillation, absorption with 2-ethylhexanol, and liquid-liquid extraction (LLX) with DIPE or 1-octanol as solvent. All options are simulated with Aspen Plus and evaluated on energy consumption, irrecoverable solvent loss, total number of unit operations needed in the separation train, product purity, and utility costs. The comparison is shown in Table 4. Distillation

\section{Table 4. Separation Train Alternatives for the LA Route}

\begin{tabular}{lllcc} 
& $\begin{array}{c}\text { design 1 } \\
\text { (dist) }\end{array}$ & $\begin{array}{c}\text { design 2 } \\
\text { (LLX-Oct) }\end{array}$ & $\begin{array}{c}\text { design 3 } \\
\text { (LLX-DIPE) }\end{array}$ & $\begin{array}{c}\text { design 4 } \\
\text { (absorption) }\end{array}$ \\
$\begin{array}{c}\text { no. of units } \\
\begin{array}{c}\text { AcrA purity } \\
{[\mathrm{wt} \%]}\end{array}\end{array}$ & 3 & 7 & 8 & 3 \\
$\begin{array}{c}\text { energy } \\
\text { consumption }\end{array}$ & 84 & 99.1 & 99.7 & 85.8 \\
$\begin{array}{c}{[\mathrm{MW}]} \\
\text { product recovery } \\
{[\mathrm{wt} \%]}\end{array}$ & 99.7 & 99.88 & 99.5 & 99.97 \\
$\begin{array}{c}\text { solvent loss } \\
{[\mathrm{kg} / \mathrm{h}]}\end{array}$ & - & 1162 & 1904 & 2575 \\
$\begin{array}{c}\text { utility costs } \\
{[\$ / \mathrm{t} \text { AcrA }]}\end{array}$ & 430 & 400 & 330 & 500 \\
\hline
\end{tabular}

(design 1) and absorption (design 4) are rejected in an early stage due to high energy consumption and inability of reaching desired product specifications. Simulations show that the use of 1-octanol as a solvent (design 2) yields high energy consumption without reaching the target purity, while DIPE (design 3 ) reaches the purity with substantially less energy consumption. After summarizing the cost per metric ton of product, DIPE is chosen as the extraction solvent. Unfortunately, this alternative uses the largest amount of unit operations, but the operating costs are substantially lower. An electricity price of $\$ 0.06 / \mathrm{kWh}$ and solvent prices for 1octanol and DIPE of $\$ 1,000 / \mathrm{t}$ solvent are assumed.

4.1.4. Heat Integration. According to the composite curve given in Figure 3, the heating and cooling requirements are 4.75 and $141 \mathrm{MW}$ after heat integration. The amount of heat that can be integrated is equal to $55 \mathrm{MW}$. Almost all the streams are heated by the hot stream of $365^{\circ} \mathrm{C}$ leaving the dehydration reactor. The only exception is the heating of the dehydration reactor itself, which calls for an external heating utility, provided by the combustion of natural gas. The available energy from the liquid phase oxidation reactor at 80

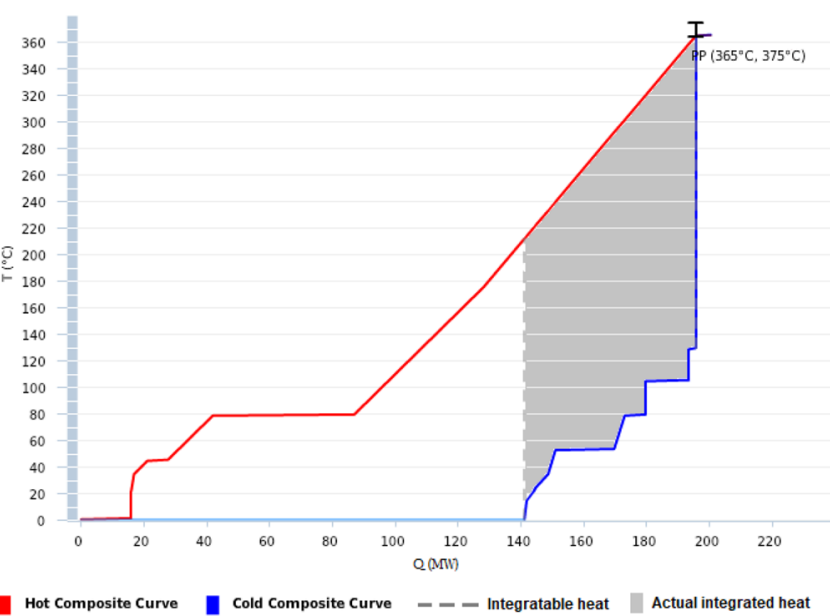

Figure 3. Composite curves of the LA route.

${ }^{\circ} \mathrm{C}$ (left red horizontal line segment at $80{ }^{\circ} \mathrm{C}$ ) is not useful for heat integration. Energy available at this low temperature cannot be used for steam generation. Moreover, the oxidation reactor needs to be cooled, introducing a high cooling requirement.

4.2. AOL Route. 4.2.1. Flow Sheet Description. In Figure 4 , a simplified version of the flow sheet can be found including a stream table (Table 5). The process starts with the two reactors, for dehydration operated at $T=350{ }^{\circ} \mathrm{C}$ and oxidation at $T=325{ }^{\circ} \mathrm{C}$. Due to the assumed high conversion in the dehydration reactor, separation between the reactors is not necessary. The reactions are assumed to require a high level of dilution based on literature data, which shows that higher dilution enhances catalytic performance by assisting desorption of acrylic acid from the catalyst surface ${ }^{2}$ and limiting coke formation. ${ }^{19}$ Therefore, extra water is added before R-1 (2). In front of the second reactor an air and water stream is added to provide oxygen and more dilution via the nitrogen and water (5). The presence of nitrogen in the feed further increases the operation safety by narrowing the explosion envelope. In the second reactor, several side reactions take place, consuming all the available oxygen and producing water. Examples of these reactions are the oxidation of the intermediates PAL and POL. An overview of all side reactions can be found in the full report available on request. ${ }^{11}$

The separation section starts with a flash vessel (F-1) to remove all the gases (8), and then the water with acids is fed (9) to the LLX column (LL-1) with 1-octanol as solvent. The water exiting LL-1 (11) is at a high purity and is recycled to the reaction section. The recycle of water in the mass balance is not closed to limit computational time. This is acceptable since the compositions of the fresh water (2 and 5) and recycle water (11) are sufficiently identical for process analysis. To make up for the solvent loss in the solvent purge (21) and the separation section, fresh solvent is added by stream 10. After LL-1 the solvent, carboxylic acids, and the leftover water (12) are distilled in a vacuum distillation column (D-1), where the water with acetic acid (AceA) is removed at the top (14) and the bottom consists of the solvent, AcrA, PrA, and the heavies (13). A second vacuum distillation column (D-2) is used to recover the solvent at the bottom to recycle it to LL-1 (16). A third vacuum distillation (D-3) is used to remove the heavies (18). For the last separation of the mixture of AcrA and PrA, a crystallization unit $(\mathrm{C}-1)$ is used. The product ends up in 


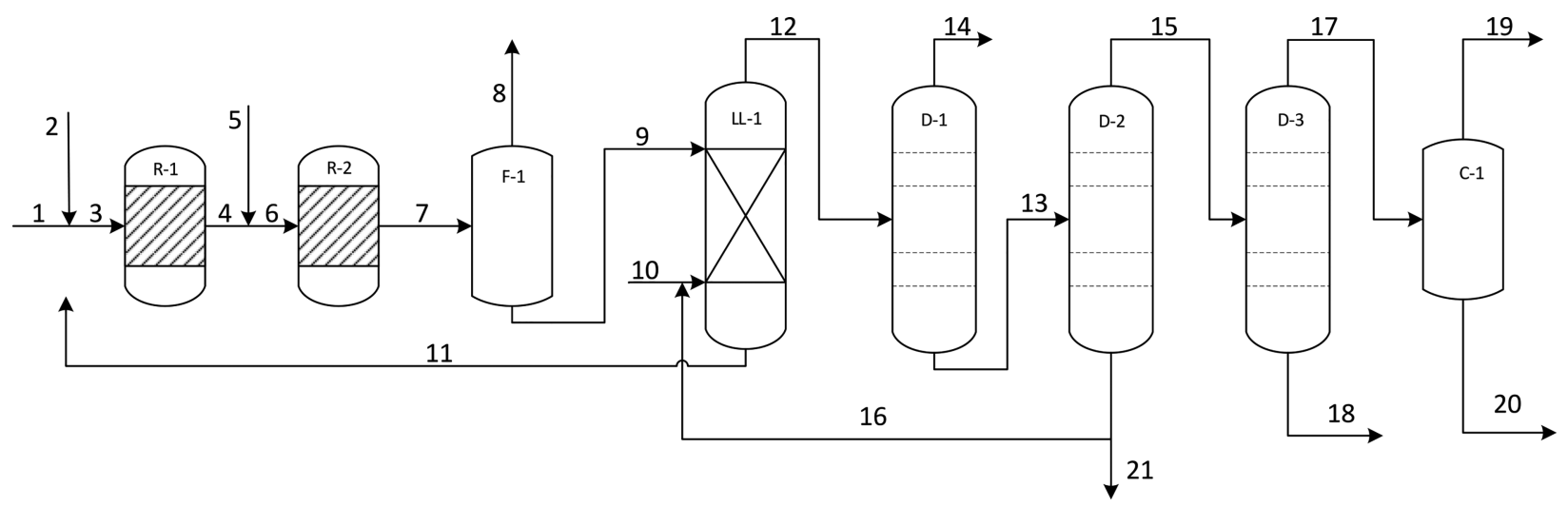

Figure 4. Simplified process flow diagram of the AOL route. Pumps, compressors, and heat exchangers are not shown.

stream 20. The compositions of selected streams can be found in Table 5.

4.2.2. Reactor Design. As kinetic data for the reactions at hand is unavailable, only a high level design of the reactors is made based on an estimated kinetic rate, based on a similar reaction system. More details can be found in the full report available on request. ${ }^{11} \mathrm{~A}$ multitubular fixed bed reactor at 350 ${ }^{\circ} \mathrm{C}$ is chosen for the gas phase dehydration of PG to AOL. It will ensure sufficient heating to prevent the adiabatic temperature decrease of $150 \mathrm{~K}$, which is important to reach the desired conversion. The heat duty of the dehydration reactor is $6 \mathrm{MW}$. In the gas phase oxidation reactor, the adiabatic temperature rise is $600 \mathrm{~K}$. It is expected that a fluidized bed reactor is needed for adequately removing 36 MW of heat at $325{ }^{\circ} \mathrm{C}$. Furthermore, safety measures such as thorough temperature control and shutdown options are necessary.

4.2.3. Main Separation Unit. After the reactor section, the process gas stream (7) consists mainly of water and only 13.4 wt \% AcrA. To remove as much water as possible from the mixture, three different separation alternatives were evaluated. An absorption with 2-ethylhexanol, a liquid-liquid extraction using 1-octanol, and a distillation model are compared in Table 6 . The solvents were chosen based on the interaction with the carboxylic acid and hydrophobicity based on data found in the literature $^{29}$ and tested by simulations in Aspen Plus. Parameters such as heat duty, product recovery, and irrecoverable solvent losses were used as performance indicators, since the number of operating units are equal for each case. Overall, the liquid-liquid extraction using 1-octanol showed the best results and was therefore chosen. An electricity price of $\$ 0.06 / \mathrm{kWh}$ and a solvent price for 1 octanol of $\$ 1,000 / \mathrm{t}$ solvent are assumed, equal to the LA route. Nevertheless, an extra melt crystallization step is required as a last step to reach the required product purity. The crystallization unit design is based on order of magnitude calculations, with a total of five batch columns of $30 \mathrm{~m}^{3}$ and an energy duty of $3 \mathrm{MW} .^{30}$

4.2.4. Heat Integration. The composite curve constructed for the AOL route (Figure 5) shows a possible heat integration of 96.3 MW between the hot and cold streams. The amount of heat exchangers is taken into account; therefore only 89.4 MW is integrated. This makes that 52.1 MW of external cooling and 13.4 MW of hot utility are required. For safety reasons it would be better if the heat of the oxidation reactor is not integrated, because of severe hazards when a runaway reaction occurs. Currently this stream also heats up the feed stream to the first reactor. However, the costs of external utilities will increase by $7.5 \mathrm{MM} \$$ /year or $35 \mathrm{\$} / \mathrm{t} \mathrm{PG}$, if the heat from the oxidation reactor is not integrated. A relatively easy and cheap solution for this safety issue is to implement an extra feed-effluent heat exchanger, only using a cold utility when a runaway would emerge. $^{31}$

\section{EVALUATION}

Both processes are evaluated on technical (water footprint, solvent losses, heat integration) and economic (CAPEX, OPEX, break-even price) aspects.

5.1. Economic Aspects. The CAPEX for both routes is depicted in Figure 6. The reactor system is a major cost contributor to the equipment cost for both routes. Only limited information is available to make proper reactor design possible. The kinetic data on relevant reactions is for example not available. Hence, one can expect them to be susceptible to further optimization and cost reduction.

The spray evaporator unit in the LA route is incorporated into the overall reactor costs. Nevertheless, the reactor costs for the AOL route are estimated to be higher due to the required heat management and larger size in the oxidation reactor (gas phase in the AOL route and liquid phase in the LA route).

Another major assumption is in the cost of the catalysts which are assumed to be part of the CAPEX due to a long lifespan and high investment cost. Both routes use one expensive catalyst (HZSM-5 for the LA route and $\mathrm{Sc}_{2} \mathrm{O}_{3}$ for the AOL route). To make a fair comparison, it is assumed that the costs of the catalysts for both routes equals $5 \mathrm{MM} \$$ for two reactors, since the knowledge on the catalysts is too limited to distinguish between the two routes yet.

Furthermore, a large difference can be seen in the pumps and compressors, which are much more expensive in the LA route. This is mainly due to the use and recycle of a larger amount of solvent, in which one compressor is necessary during solvent recycling. Moreover, the LA route includes an ASU to provide pure oxygen. Investing in an ASU is found to be economically favorable over buying pure oxygen from an external supplier. The need for a solid removal unit in the LA route is not considered to have a significant impact on the project CAPEX, since the FOB costs of a vacuum drum filter are found to be $130 \mathrm{k} \$$ by cost correlation. The OPEX for the solid removal unit covers the needed acid, but not the power consumption and vacuum utility. The last two are assumed to be negligible. 
Table 6. Separation Train Alternatives for the AOL Route

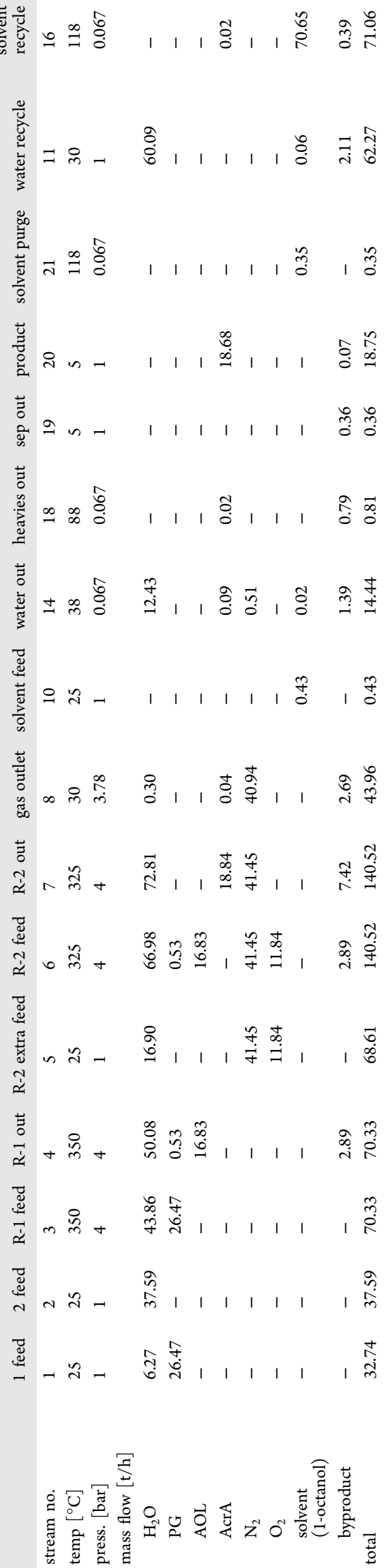

$\begin{array}{lccc} & \begin{array}{c}\text { design 1 } \\ \text { (absorption) }\end{array} & \begin{array}{c}\text { design 2 } \\ \text { (LLX-Oct) }\end{array} & \begin{array}{c}\text { design 3 } \\ \text { (dist) }\end{array} \\ \begin{array}{l}\text { no. of units } \\ \text { AcrA purity [wt \%] }\end{array} & 4 & 4 & 4 \\ \begin{array}{l}\text { energy consumption } \\ {[\text { MW] }}\end{array} & 98.6 & 99.1 & 99.7 \\ \begin{array}{l}\text { product recovery } \\ {[\text { mol \%] }}\end{array} & 87.4 & 33 & 267 \\ \begin{array}{l}\text { solvent loss [kg/h] } \\ \text { utility costs [\$/t AcrA] }\end{array} & 2267 & 99.5 & 99.6 \\ \end{array}$

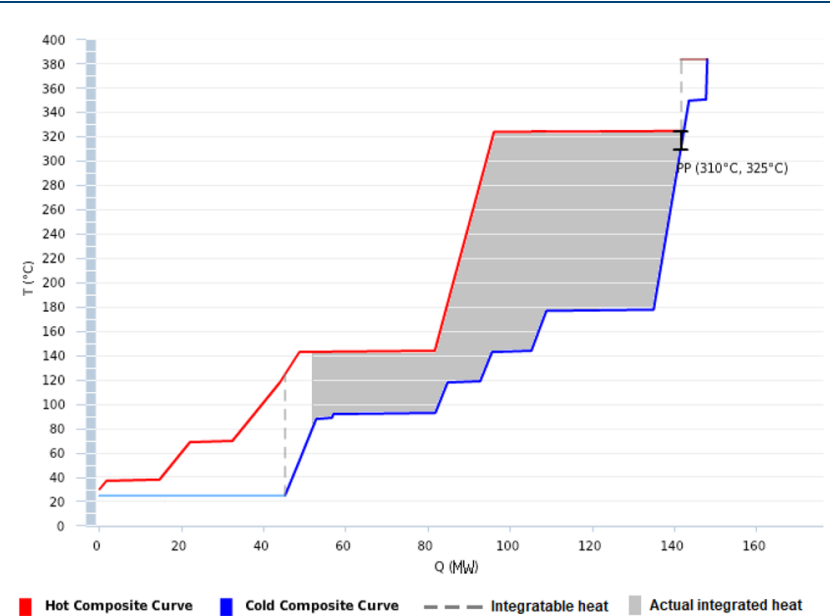

Figure 5. Composite curves of the AOL route.

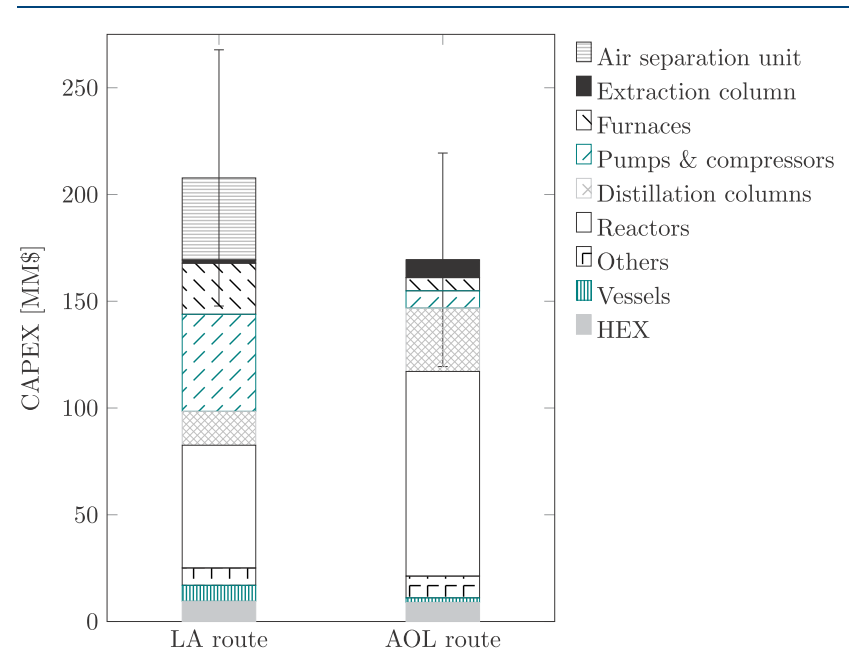

Figure 6. Breakdown of capital inside battery limits (ISBL) expenditures for LA and AOL routes in MM\$. The error bars represent an uncertainty of $30 \%$.

Overall, the CAPEX of the LA route is higher than that for the AOL route. However, the difference is within the accuracy of the used method of around $30 \%$. The relative error margin between the two estimations will probably be smaller, since the same method is used for both routes and both processes use similar equipment.

Figure 7 represents the estimated annual operation costs for both routes. The raw materials represent the PG feed, whereas consumables are other chemicals that are needed in the process, such as the solvent makeup and the acidifier in the LA process. The contributions of the utilities, consumables, and fixed cost of production-which are estimated here based on 


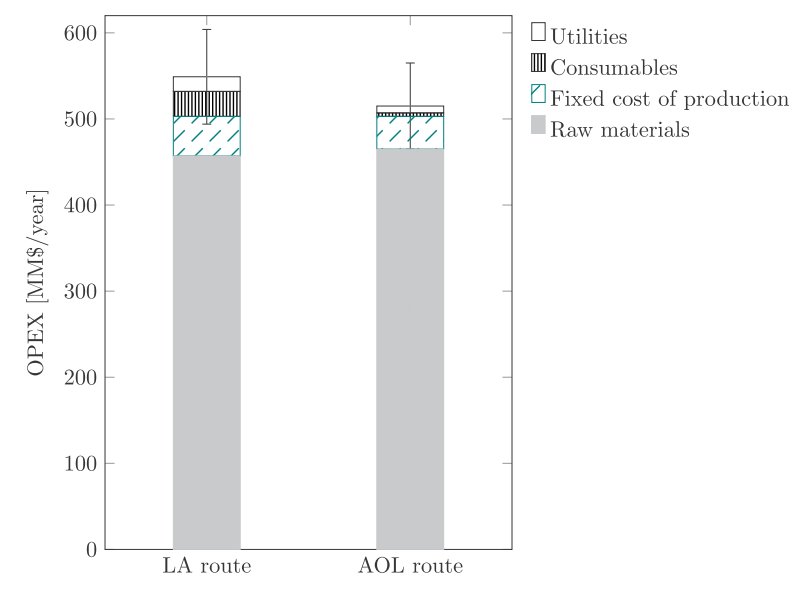

Figure 7. Breakdown of operational expenditures for LA and AOL routes in MM\$, using a PG price of $\$ 2,200 / t$. The error bars represent an uncertainty of $10 \%$.

the total CAPEX - are indeed higher for the LA route. The LA route requires acidification of the LA salt, loses more solvent (both consumables), consumes much fuel to power the evaporator (utilities), and has higher total CAPEX (fixed cost of production).

The detailed economic analysis suggests room for process improvements. Both routes would economically benefit from reduction of the water usage, which would result in significant savings in sizing of equipment, heat duty, and cooling utilities. The LA route could benefit from an improved approach to LA evaporation and from avoiding the need for LA acidification. The AOL route would benefit from avoiding the crystallization unit.

5.1.1. Sensitivity Analysis. Figure 8 represents the cost correlation per metric ton of acrylic acid for a varying PG

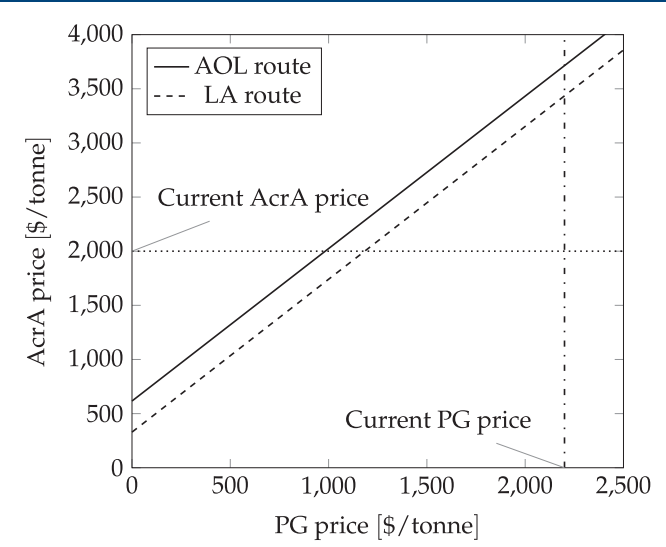

Figure 8. Price relation of pure PG price and production cost for both routes.

market price. The $y$-intersect indicates the sum of all annual operating costs including a depreciation in 10 years, except for the raw materials, normalized by the capacity of $150 \mathrm{kta}$. Since both processes are assumed to operate with similar overall yields, their economics show a similar dependency on PG price. The break-even prices for PG are found to be $\sim \$ 1,000 / t$ pure PG for the LA route and $\sim \$ 1,200 / \mathrm{t}$ pure PG for the AOL route, taking into account the current AcrA market price of $\$ 2,200 / t$. This PG price is only half of today's PG market price of $\$ 2,000 / \mathrm{t}$ but is higher than today's EG market price of
$\$ 1,000 / t$. Hence, these processes could become economically attractive once sugar hydrolysis can deliver a mix of PG and $\mathrm{EG}$ at a production cost around $\$ 1,000 / \mathrm{t}$. Figure 8 further suggests the limited impact of CAPEX and OPEX, beyond PG cost, on the overall manufacturing cost. Analysis of the sensitivity toward CAPEX and OPEX, beyond PG cost, would result in new lines parallel to those shown in Figure 8 but are only offset at zero PG price.

Figure 9 demonstrates demonstrates that the AOL route is more advantaged as it can afford a higher PG price than the LA

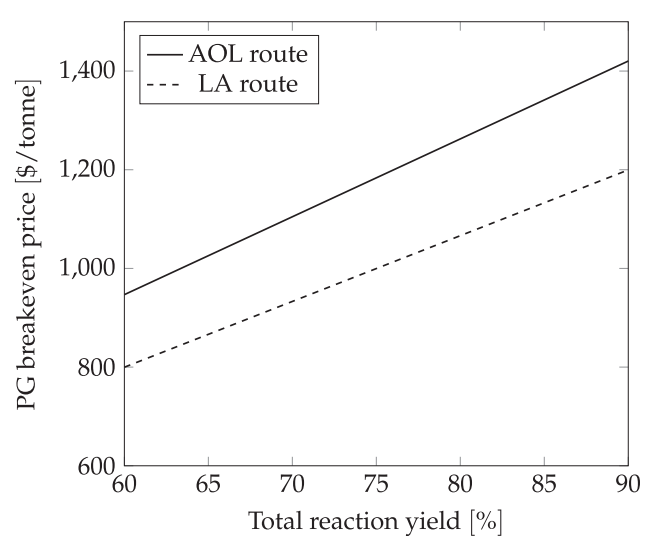

Figure 9. Pure PG break-even price for different total reaction yields compared for the LA and AOL routes.

route at an identical yield within a realistic range of $60-90 \%$. In fact, the LA route needs to deliver $10-15$ percentage points higher yield than the AOL route within the evaluated range to reach the same break-even PG price.

The break-even PG price depends directly on the OPEX costs, which consists of fixed costs (depending on the CAPEX), utilities, consumables, and raw materials. The cost of the PG feed represents 83 and $90 \%$ of the total OPEX costs for the LA and AOL routes in the base case, respectively. This shows that the CAPEX has a limited influence on the breakeven PG price. It also explains the lower slope of the breakeven PG price versus yield for the LA route in Figure 9.

5.2. Technical Aspects. Table 7 summarizes the results for the comparison between the LA and AOL route. Table 7 is explained in sections 5.2.1-5.2.4.

Table 7. Comparison of LA Route and AOL Route

\begin{tabular}{|c|c|c|c|}
\hline description & units & $\begin{array}{l}\mathrm{LA} \\
\text { route }\end{array}$ & $\begin{array}{l}\text { AOL } \\
\text { route }\end{array}$ \\
\hline water/product ratio & [ $\mathrm{t}$ of water/ $\mathrm{t}$ of product $]$ & 5.1 & 3.9 \\
\hline water/PG feed ratio & {$[\mathrm{t}$ of water/t of $\mathrm{PG}]$} & 3.5 & 1.6 \\
\hline recycled water & {$[\%]$} & 96 & 75 \\
\hline solvent losses & [ $\mathrm{kg}$ of solvent/t of product $]$ & 139 & 23 \\
\hline heat integrated & {$[\mathrm{MW}]$} & 55 & 89 \\
\hline $\begin{array}{l}\text { required hot utility after } \\
\text { integration }\end{array}$ & {$[\mathrm{MW}]$} & $4^{a}$ & 13 \\
\hline $\begin{array}{l}\text { required cold utility after } \\
\text { integration }\end{array}$ & {$[\mathrm{MW}]$} & 141 & 52 \\
\hline $\begin{array}{l}\text { overall heat exchange } \\
\text { duty }\end{array}$ & {$[\mathrm{MW}]$} & 196 & 141 \\
\hline
\end{tabular}

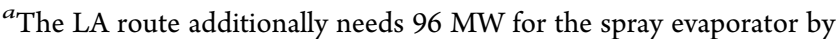
burning natural gas, which is not taken into consideration in the heat integration but is included in the OPEX. 
5.2.1. Water Footprint. The water footprint for the LA and AOL route is largely depending on the size of the water recycle, which is respectively 100 and $59 \mathrm{t} / \mathrm{h}^{2}$. The high levels of dilution are introduced in the LA route to prevent LA polymerization $^{32}$ between the two reactors and in the AOL route to ensure a good catalyst performance. These water concentrations are solely based on assumptions referenced from experimental work. Less diluted solutions will lead to energy savings and smaller unit sizes resulting in lower OPEX and CAPEX. However, experimental data to evaluate the feasibility of the process will be needed. Therefore, conclusions drawn on solvent losses and energy demand need to be taken with caution, since these parameters are largely influenced by the amount of water present in the process. Developing low temperature dehydration catalysts might decrease the process temperature and, therefore, the required amount of dilution.

5.2.2. Solvent Losses. Both routes have been designed independently from one another. This explains the difference in solvent selection: DIPE for the LA route and 1-octanol for the AOL route. The higher water solubility of DIPE $(8.8 \mathrm{~g} / \mathrm{L})$ vs 1-octanol $(0.3 \mathrm{~g} / \mathrm{L})$ is responsible for the high solvent losses; see Table 7. Furthermore, the LA process has been designed to operate at twice the dilution of the AOL route (see section 5.2.1) and, thereby, uses about twice the amount of solvent. A broader and more thorough analysis of potential solvents, accompanied by experimental validation and determination of critical binary interactions, could further improve the economics.

5.2.3. Heat Integration. The largest difference in heat integration is related to utilizing the heat of the oxidation reaction. In the LA route the oxidation is performed at low temperatures, making the energy produced useless and even resulting in costs for cooling. The oxidation reaction in the AOL route is performed at high temperatures, producing valuable energy. The heat produced in the reaction is mainly used to heat the feed of the first reactor. Using the heat of an oxidation reaction is not without risks, since a runaway reaction could not be contained without extra safety precautions. The LA route is in that case inherently safer than the AOL route, since it does not integrate the heat of the reactors and operates at a lower temperature. The AOL route safety could be ensured by installing an additional heat exchanger which cools the reactor in case of emergency, as mentioned before.

While the LA route does not provide very good options for heat integration, it provides opportunities for steam export. In contrast to what is proposed in Figure 3, the high-temperature section of the hot dehydration effluent can first be used for generating $67 \mathrm{MW}$ of steam at $180{ }^{\circ} \mathrm{C}$. Subsequently, the remaining energy available from the dehydration effluent is still sufficient to satisfy the complete heating requirement by heat integration. The revenue obtained from this steam, almost 12 $\mathrm{MM} \$ /$ year or $55 \$ / \mathrm{t}$ PG can easily pay for the cost of the additional heat exchanger area required.

5.2.4. Catalyst Performance. As indicated in section 2, the yield is assumed to be the same for both processes. Since a major economic parameter of the processes is the overall yield through the cost of the feedstock (Figure 7), the preferred process will be the one that eventually uses the most selective catalyst combination. Further catalyst research is therefore necessary, particularly for the AOL route that is currently the least advanced.
To conclude, looking at the process flow diagrams both processes have marginal differences in sequence and unit operations. However, the current level of technical evaluation suggests more favorable values in water usage, solvent losses, heat integration, and consequently OPEX and CAPEX for the AOL route. Accordingly, the AOL route could be break-even at a slightly higher $(+\$ 200 / t)$ PG feed price compared to the LA route, which is favorable for the AOL route.

\section{CONCLUSION}

A comparison of two production routes from propylene glycol to acrylic acid is performed. Considering a reaction yield of 75.1\% to AcrA for both routes, the required PG break-even prices are found to be $\$ 1,000 / \mathrm{t}$ and $\$ 1,200 / \mathrm{t}$ for respectively the LA route and the AOL route, which makes the AOL route more promising. Lactic acid was found to be a more complicated intermediate due to its tendency of polymerization and the need for acidification. This process-specific complexity is reflected in the difference in calculated capital and operational expenditures.

Major challenges in the proposed production processes are related to the catalyst performance and the level of dilution. Evaluation of different catalysts is required for all reactions involved in the processes. Reliability of the current process designs can significantly be improved by increasing the amount of experimental data. Research needs to be focused on kinetics, byproducts, stability, and performance.

Moreover, the large amounts of dilution have a negative effect on the cost competitiveness of these biobased production processes. High levels of dilution are used in the current designs to avoid LA polymerization in the LA route and coke formation in the AOL route. Lower levels of dilution will lead to a decrease in CAPEX and energy consumption. Finally, this will be translated to a higher break-even PG price that the process can handle and thus a more attractive process from an economic point of view.

\section{ASSOCIATED CONTENT}

\section{S Supporting Information}

The Supporting Information is available free of charge at https://pubs.acs.org/doi/10.1021/acs.iecr.9b04334.

Overview of catalyst research and tables with basic properties of all unit operations including their cost (PDF)

\section{AUTHOR INFORMATION}

\section{Corresponding Author}

*E-mail: a.g.j.vanderham@utwente.nl.

ORCID

J. D. Wendt: 0000-0002-2183-5205

J.-P. Lange: 0000-0001-6567-2957

\section{Author Contributions}

${ }^{\S}$ M.M.B, E.D., D.G.T, H.I.S., J.D.W., and R.J.D.R.: These authors contributed equally.

\section{Notes}

The authors declare no competing financial interest.

\section{LIST OF ABBREVIATIONS}

2,3-PD = pentanedione

$\mathrm{AOL}=$ allyl alcohol

AceA $=$ acetic acid 
AcrA = acrylic acid

$\mathrm{AL}=$ acetylaldehyde

DIPE = diisopropyl ether

DPG = dipropylene glycol

$\mathrm{EG}=$ ethylene glycol

$\mathrm{FA}=$ formic acid

$\mathrm{LA}=$ lactic acid

LLX = liquid-liquid extraction

MCP = methyl cyclopentenone

$\mathrm{PAL}=$ propanal

PG = propylene glycol

PLA = polylactic acid

POL $=1$-propanol

$\operatorname{PrA}=$ propionic acid

$\Delta T_{\mathrm{ad}}=$ adiabatic temperature rise

\section{REFERENCES}

(1) Straathof, A. J. J.; Sie, S.; Franco, T. T.; van der Wielen, L. A. M. Feasibility of acrylic acid production by fermentation. Appl. Microbiol. Biotechnol. 2005, 67, 727-734.

(2) Pramod, C. V.; Fauziah, R.; Seshan, K.; Lange, J.-P. Bio-based acrylic acid from sugar via propylene glycol and allyl alcohol. Catal. Sci. Technol. 2018, 8, 289-296.

(3) Liu, L.; Ye, X. P.; Bozell, J. J. A Comparative Review of Petroleum-Based and Bio-Based Acrolein Production. ChemSusChem 2012, 5, 1162-1180.

(4) United States Department of Agriculture. Sugar: World Markets and Trade. 2018. https://apps.fas.usda.gov/psdonline/circulars/ sugar.pdf. Record Stocks and consumption despite lower production.

(5) Ruppert, A. M.; Weinberg, K.; Palkovits, R. Hydrogenolysis Goes Bio: From Carbohydrates and Sugar Alcohols to Platform Chemicals. Angew. Chem., Int. Ed. 2012, 51, 2564-2601.

(6) Wang, A.; Zhang, T. One-Pot Conversion of Cellulose to Ethylene Glycol with Multifunctional Tungsten-Based Catalysts. Acc. Chem. Res. 2013, 46, 1377-1386.

(7) Beroe. Propylene Glycol Market Intelligence. 2017. https:// www.beroeinc.com/category-intelligence/propylene-glycol-market/.

(8) Hurley, M. Europe MEG market in stalemate as ethylene August contract still unsettled. 2018. https://www.icis.com/explore/ resources/news/2018/07/31/10246261/europe-meg-market-instalemate-as-ethylene-august-contract-still-unsettled/.

(9) Douglas, J. M. Conceptual Design of Chemical Processes, 1st ed.; McGraw-Hill Book Co.: 1988.

(10) Lopez Montoya, S.; Buitelaar, M.; Brooks, A.; van Putten, J.; Stokvis, H. Acrylic Acid Production from Monopropylene Glycol; PPD report; University of Twente: $2018 ; 170 \mathrm{pp}$. Available on request at the corresponding author.

(11) van Daatselaar, E.; Kamphuis, E.; de Sousa Ribeiro, R.; van Teijlingen, D.; Wendt, J. Process Design for Acrylic Acid from Propylene Glycol via Allyl Alcohol; PPD report; University of Twente: 2018; 146 pp. Available on request at the corresponding author.

(12) Arkema Innovative Chemistry. Glacial Acrylic Acid FG. https://www.arkema.com/export/shared/.content/media/ downloads/products-documentations/acrylicmonomers/GlacialAcrylic-Acid-Asia.pdf.

(13) Seider, W.; Seader, J.; Lewin, D.; Widagdo, S. Product and Process Design Principles: Synthesis, Analysis and Design; John Wiley \& Sons: 2010.

(14) Sinnott, R.; Towler, G. Chemical Engineering Design: SI Edition; Chemical Engineering Series; Elsevier Science: 2009.

(15) Jenkins, S. CEPCI Updates: January 2018 (preliminary) and December 2017 (final). Chemical Engineering Online. 2018; http:// www.chemengonline.com/cepci-updates-january-2018-prelim-anddecember-2017-final/.

(16) Feng, Y.; Yin, H.; Gao, D.; Wang, A.; Shen, L.; Meng, M. Selective oxidation of 1,2-propanediol to lactic acid catalyzed by hydroxylapatite nanorod-supported $\mathrm{Au} / \mathrm{Pd}$ bimetallic nanoparticles under atmospheric pressure. J. Catal. 2014, 316, 67-77.

(17) Yuan, C.; Liu, H.; Zhang, Z.; Lu, H.; Zhu, Q.; Chen, Y. Alkalimetal-modified ZSM-5 zeolites for improvement of catalytic dehydration of lactic acid to acrylic acid. Chinese Journal of Catalysis 2015, 36, 1861-1866.

(18) Zeng, F.; Bossmann, S. H.; Heidlage, M. G.; Hohn, K. L. Transformation of 2,3-butanediol in a dual bed catalyst system. Chem. Eng. Sci. 2018, 175, 387-395.

(19) Li, X.; Zhang, Y. Highly Efficient Process for the Conversion of Glycerol to Acrylic Acid via Gas-Phase Catalytic Oxidation of Allyl Alcohol Intermediate. ACS Catal. 2016, 6, 143-150.

(20) Gmehling, J.; Onken, U. Vapor-liquid Equilibrium Data Collection. DECHEMA Chemistry Data Series; DECHEMA: 1967; Vol. 1 .

(21) Gmehling, J.; Onken, U.; Rarey-Nies, J. Vapor-liquid Equilibrium Data Collection. DECHEMA Chemistry Data Series; DECHEMA: 1977; Vol. 1.

(22) Kemp, I. Pinch Analysis and Process Integration; ButterworthHeinemann: 2006.

(23) Pereira, P. M.; Gernandes, M. C.; Matos, H. A. FI²EPI - A freeware tool for performing Heat Integration based on Pinch Analysis. Proceedings of the 26th European Symposium on Computer Aided Process Engineering - ESCAPE 26; Elsevier: 2016.

(24) Woods, D. R. Rules of Thumb in Engineering Practice; WileyBlackwell: 2007; pp 376-436.

(25) Matche. Matches' Process Equipment Cost Estimates. 2014; http://www.matche.com/equipcost.

(26) Peters, M. S.; Timmerhaus, K. D.; West, R. E. Plant Design and Economics for Chemical Engineers, 4th ed.; McGraw-Hill Companies Inc.: 1991; p 923.

(27) Schlüter, S.; Steiff, A.; Weinspach, P.-M. Heat transfer in twoand three-phase bubble column reactors with internals. Chem. Eng. Process. 1995, 34, 157-172.

(28) Godlewski, J. E. Process for production of acrylic acid or its derivatives. U.S. Patent US9452967, 2013.

(29) Fischer, K. J.; Lange, J.-P.; Van Rossum, G.; Schoonebeek, R. J.; Golf, C. P. Carboxylic acid absorption from vaporous aqueous streams. World Patent WO2017114829A1, 2017.

(30) Le Page Mostefa, M.; Muhr, H.; Plasari, E.; Fauconet, M. A purification route of bio-acrylic acid by melt crystallization respectful of environmental constraints. Powder Technol. 2014, 255, 98-102.

(31) Luyben, W. L. New Control Structure for Feed-Effluent Heat Exchanger/Reactor Systems. Ind. Eng. Chem. Res. 2012, 51, 85668574.

(32) Vu, D. T.; Kolah, A. K.; Asthana, N. S.; Peereboom, L.; Lira, C. T.; Miller, D. J. Oligomer distribution in concentrated lactic acid solutions. Fluid Phase Equilib. 2005, 236, 125-135. 